OPEN ACCESS

Edited by:

Anastasia N. Vlasova

The Ohio State University,

United States

Reviewed by:

Michalis Barkoulas,

Imperial College London,

United Kingdom

Céline Nadia Martineau,

INSERM U1104 Centre

d'immunologie de Marseille-Luminy

(CIML), France

*Correspondence:

Cheng-Ju Kuo

chengjukuo@gmail.com

Chang-Shi Chen

cschen@mail.ncku.edu.tw

Specialty section:

This article was submitted to

Comparative Immunology,

a section of the journal

Frontiers in Immunology

Received: 12 May 2020

Accepted: 21 October 2020

Published: 30 November 2020

Citation:

Kuo C-J, Hsu Y-C, Wang S-T, Liou B-Y, Lim SBY, Chen Y-W and Chen C-S (2020) IGLR-2, a Leucine-

Rich Repeat Domain Containing

Protein, Is Required for the Host Defense in Caenorhabditis elegans.

Front. Immunol. 11:561337. doi: 10.3389/fimmu.2020.561337

\section{IGLR-2, a Leucine-Rich Repeat Domain Containing Protein, Is Required for the Host Defense in Caenorhabditis elegans}

\author{
Cheng-Ju Kuo ${ }^{1,2 *}$, Ya-Chu Hsu ${ }^{1}$, Sin-Tian Wang ${ }^{2}$, Bang-Yu Liou ${ }^{1}$, \\ Serene Boon-Yuean Lim ${ }^{1}$, Yi-Wei Chen ${ }^{2}$ and Chang-Shi Chen ${ }^{1,2 *}$ \\ ${ }^{1}$ Department of Biochemistry and Molecular Biology, College of Medicine, National Cheng Kung University, Tainan, Taiwan, \\ 2 Institute of Basic Medical Sciences, College of Medicine, National Cheng Kung University, Tainan, Taiwan
}

Enterohemorrhagic Escherichia coli (EHEC), a human pathogen, also infects Caenorhabditis elegans. We demonstrated previously that $C$. elegans activates the p38 MAPK innate immune pathway to defend against EHEC infection. However, whether a C. elegans pattern recognition receptor (PRR) exists to regulate the immune pathway remains unknown. PRRs identified in other metazoans contain several conserved domains, including the leucine-rich repeat (LRR). By screening a focused RNAi library, we identified the IGLR-2, a transmembrane protein containing the LRR domain, as a potential immune regulator in $C$. elegans. Our data showed that iglr-2 regulates the host susceptibility to EHEC infection. Moreover, iglr-2 is required for pathogen avoidance to EHEC. The iglr-2 overexpressed strain, which was more resistant to EHEC originally, showed hypersusceptibility to EHEC upon knockdown of the p38 MAPK pathway. Together, our data suggested that iglr-2 plays an important role in $C$. elegans to defend EHEC by regulating pathogen-avoidance behavior and the p38 MAPK pathway.

Keywords: Caenorhabditis elegans, iglr-2, innate immunity, p38 MAPK pathway, enterohemorrhagic Escherichia coli

\section{INTRODUCTION}

Animal hosts constantly encounter a variety of pathogenic microorganisms. Appropriate sensing of pathogenic microbes and an effective response to infection are crucial for their survival. The receptors through which metazoans detect pathogen/microbe-associated molecular patterns (PAMPs/MAMPs) or damage-associated molecular patterns (DAMPs) are called pattern recognition receptors (PRRs) $(1,2)$. PRRs mediate the launch of innate immune response resulting in antimicrobial peptide expression while recognizing PAMPs or DAMPs (2). This process is called pattern-triggered immunity (PTI) (1). Intriguingly, no related receptors responsible for pathogen sensing have yet been identified in C. elegans. Although the receptors that function upstream of the immunity pathway remain unknown, several pieces of evidence imply that PTI exists in C. elegans. It has been reported that the intact LPS of Salmonella enterica is required for the induction of p38 MAPK immunity pathway during infection in C. elegans $(3,4)$. This suggested that the upstream receptors detect bacterial LPS to activate immune response. 
Pseudomonas aeruginosa secretes toxins to kill C. elegans. However, a study showed the secreted factors of $P$. aeruginosa in medium did not induce an immune response, but exposure to a non-pathogenic Pseudomonas mendocina did upregulate several specific immune-related genes (5). In addition, nematodes were found to induce $56 \%$ of identical genes (e.g., antifungal genes) while infected with either live or heat-killed Candida albicans via transcriptomic analysis (6). Congruent with these results, heat-killed Staphylococcus aureus stimulated a similar immune response as live S. aureus to C. elegans (7). These studies indicate that $C$. elegans detects pathogens by targeting not only toxins but also some pathogenic components. C. elegans can also trigger distinct host defense responses while facing different pathogenic insults (7-9). Moreover, recent reports also demonstrated that C. elegans can sense intracellular DNA and RNA to activate a DAMP and PAMP response $(10,11)$. These lines of evidence suggest that C. elegans might have unique receptors for sensing either pathogens or their products to mount PAMP or DAMP responses.

PRRs from different species share specific evolutionarily conserved motifs or domains, which are usually unique to microbes for recognizing conserved molecular structures of pathogenic microbes (e.g., bacterial flagellin, bacterial LPS or viral ssRNA). The most well-known pathogen recognition domain is the leucine-rich repeat (LRR) domain. The toll-like receptor (TLR) family, the NOD-like receptor family (NLR) in animals and the leucine-rich repeat receptor-like kinase (LRRRLK) in plants contain LRR domains. TLRs were first discovered in Drosophila melanogaster to recognize microbial patterns as well as the endogenous ligand, Spatzle [or Spaetzle, Spätzle (Spz)] triggering the host defense response and have since been found in many other species (12). In humans, TLRs are located on the cell membrane or in the endosome where they sense specific PAMPs/MAMPs to activate the nuclear factor- $\kappa \mathrm{B}(\mathrm{NF} \kappa \mathrm{B})$ or the p38 mitogen-activated protein kinase (MAPK) pathway (2). The LRR domain at the N-terminal tail of TLRs is responsible for the recognition of extracellular or endosomal ligands (13). Once the ligands bind to receptors, TLRs become dimerized and trigger downstream signaling activation (e.g., NF- $k$ B, IRF-7, or p38 MAPK pathway) (13). For example, while bacterial lipopolysaccharide (LPS) binds to Toll-like receptor 4, Toll/ Interleukin-1 receptor homology (TIR) domain in the cytoplasm recruits adaptor protein, MyD88, to activate NF-kB resulting in proinflammatory cytokine expression via phosphorylation cascade (14). The nucleotide-binding and oligomerization domain (NOD)-like receptor family (NLR) are the receptors located in the cytoplasm, containing NOD domain in the central, signal domain at the N-terminus and an LRR domain at the C-terminus which is involved in sensing and binding to ligands (15). Two classical NLRs, NOD1 and NOD2 receptors, are essential for recognizing diaminopimelic acid and muramyl dipeptide (both are bacterial peptidoglycan derivatives), respectively. The recognition stimulates NF- $\kappa \mathrm{B}$, interferon (IFN) regulatory factors (IRFs) and consequently MAPK pathway activation (16). Leucine-rich repeat receptorlike kinases (LRR-RLK), which are well-characterized in plants, contain an extracellular LRR domain, a transmembrane region and a cytoplasmic Ser/Thr protein kinase domain at the C-terminus (17). In Arabidopsis thaliana, bacterial flagellin binding to FLAGELLIN-SENSING 2 (FLS2), a LRR-RLK, triggers MAPK by phosphorylation cascades allowing initiation of intracellular signaling to activate antimicrobial genes and generate ROS to defend pathogen infection (18).

Our previous research demonstrated that EHEC infects C. elegans and also activates the host p38 MAPK pathway (19). However, how C. elegans perceives EHEC bacteria to activate the innate immune response per se remains elusive. Here, we identified a gene, iglr-2, that containing immunoglobulin-like, LRR and transmembrane domains is required for host defense by screening a PRR focused RNAi library. We then generated iglr-2 null mutants using CRISPR-Cas9 method and found that iglr-2 mutants were hypersensitive to EHEC and were not able to avoid EHEC Infection. Moreover, the enhanced survival of iglr-2 overexpressing strains to EHEC killing was suppressed by p38 MAPK pathway RNAi, and the hypersensitive phenotype of iglr2 null mutant was restored to wild type by the constitutive activation of p38 MAPK cascades in iglr-2 mutant. Our genetic data suggested that iglr-2 is involved in EHEC bacteria avoidance behavior and the p38 MAPK pathway acts downstream of iglr-2, partly, in C. elegans.

\section{MATERIALS AND METHODS}

\section{Bacterial and Nematode Strains}

The nematode strains used in this study are listed in Table S1. The E. coli O157:H7 clinical isolates strain EDL933 were from the Bioresource Collection and Research Center (BCRC), Taiwan. Caenorhabditis elegans strains TU3401, VP303, WM118, and SAL144 used in this work were kindly provided by the Caenorhabditis Genetics Center (CGC), which is funded by the NIH National Center for Research Resources (NCRR). iglr-2 deletion strains were generated by the CRISPR-Cas9 system as described (20,21). iglr-2 overexpressed strains, transcriptional and translational reporter strains were created by microinjection as described $(22,23)$. The genotype of the above C. elegans strains were confirmed by single worm PCR, restriction fragment length polymorphism, and sequencing analysis. C. elegans strains were maintained on nematode growth medium (NGM) agar plates using the standard laboratory E. coli strain OP50 as described (24).

\section{PRR RNA Library Construction and Screening}

Several categories of genes are reported to contain specific motifs or domains considered as PRRs or potential PRRs (2) and hence were selected into our RNAi library e.g., C-type lectin-like domains (CTLDs), galectin, lipid binding protein (LBP), leucine-rich repeat domain (LRR), lysin motif domain (LysM), and peptidoglycan recognition protein (PGRP). We utilized WormMart on WormBase to identify the genes that contained domains of LRR, LBP, LysM, galectin, or PGRP. WormMart was 
terminated in 2016; however, a similar function can be found on BioMart. The study by Schulenburg et al. was used as a reference for genes containing C-type lectin-domains (25). RNAi clones are collected from the Ahringer RNAi or constructed from the Worm ORFeome library via Gateway cloning system. The constructed PRR library was frozen in a 96-well format with $8 \%$ glycerol (Sigma-Aldrich) at $-80^{\circ} \mathrm{C}$ before use. The detailed screening method is as described and illustrated in the Supplemental Information (Figure S1). The RNAi clones and the results of screening are listed in Table S2.

\section{Survival Analysis}

All survival assays were performed as previously described (19, 26, 27). Briefly, E. coli O157:H7 EDL933 bacteria were cultured in Luria-Bertani (LB) broth for 16 to $18 \mathrm{~h}$ at $37^{\circ} \mathrm{C}$. A $30 \mu \mathrm{L}$ aliquot of bacterial culture (O.D.600 $\mathrm{nm}=2$ ) was plated on $5.0 \mathrm{~cm}$ nematode growth media (NGM) agar plates and incubated overnight at room temperature $\left(25^{\circ} \mathrm{C}\right)$. Approximately fifty synchronized late larval stage 4 (L4) to young adult animals were transferred to each plate and maintained at $20^{\circ} \mathrm{C}$. Worms were scored daily and considered as dead when animals did not respond to touch by platinum wire. Animals that crawled off the plate were scored as censored. Worms were transferred to fresh plates every day throughout the reproductive period. The assay was conducted independently at least three times with approximately 50 to 100 worms each time at $20^{\circ} \mathrm{C}$. Data represent the sum of animals in multiple experiments in the figures. The number of independent survival assays and sample sizes for each of these experiments is given in Table S3.

\section{Lawn Occupancy Assays}

The assay was conducted as previously described with slight modifications $(28,29)$. Bacterial (E. coli OP50, E. coli O157:H7 EDL933 or $P$. aeruginosa PA14) lawns were prepared by inoculating individual bacterial colonies into $3 \mathrm{~mL}$ of LuriaBertani (LB) broth and grown for 16 to $18 \mathrm{~h}$ in a $37^{\circ} \mathrm{C}$ incubator. A $30 \mu \mathrm{L}$ aliquot of bacterial culture was plated onto the center of a $10 \mathrm{~cm}$ NGM plate and kept at room temperature $\left(25^{\circ} \mathrm{C}\right)$ for $24 \mathrm{~h}$. Approximately thirty synchronized late larval stage 4 (L4) animal worms were transferred onto plates' center containing the bacterial lawn and scored after $16 \mathrm{~h}$ incubation at $20^{\circ} \mathrm{C}$. Each animal was scored as inside or outside the lawn (Occupancy Index $=\mathrm{N}$ in $/ \mathrm{N}$ total). Experiments were performed for at least three times independently.

\section{CRISPR-Cas9 System for Targeted Genome Editing}

For CRISPR disruption of iglr-2, we used the technique previously described $(20,21)$ using the plasmids, pDD162 (21) (Peft-3::Cas9 + Empty sgRNA) (plasmid number 47549 on Addgene) and PU6::unc-119_sgRNA (21) (plasmid number 46169 on Addgene). Briefly, sgRNA targeting the $6^{\text {th }}$ and $10^{\text {th }}$ exons of iglr-2 was created by using overlap extension PCR and TA cloning system. We used PU6::unc-119_sgRNA as a template, U6prom EcoRI F (5'-CGG GAA TTC CTC CAA GAA CTC GTA CAA AAA TGC TCT-3'), iglr-2 $(\mathrm{a}+\mathrm{b})$ gRNA R (5'-TTA GAT ATC GAG CAG AGA ACA AAC ATT TAG ATT TGC AAT TCA ATT ATA TAG), iglr-2 $(\mathrm{a}+\mathrm{b})$ gRNA F $\left(5^{\prime}\right.$-GTT CTC TGC TCG ATA TCT AAG TTT TAG AGC TAG AAA TAG CAA GTT A-3') and U6prom HindIII R (5'-CGG AAG CTT CAC AGC CGA CTA TGT TTG GCG T-3') to construct sgRNA targeting the $6^{\text {th }}$ exon. As above, we used U6prom EcoRI F (5'-CGG GAA TTC CTC CAA GAA CTC GTA CAA AAA TGC TCT-3'), iglr-2 cytosol sgRNA R (5' TTG AAT CCA CCA AAG AGC ACA AAC ATT TAG ATT TGC AAT TCAA TTA TAT AG-3'), iglr-2 cytosol sgRNA F (5' GTG CTC TTT GGT GGA TTC AAG TTT TAG AGC TAG AAA TAG CAA GTT A-3') and U6prom HindIII R (5'-CGG AAG CTT CAC AGC CGA CTA TGT TTG GCG T-3') to construct sgRNA targeting the $10^{\text {th }}$ exon. N2 animals were injected with about $150 \mathrm{ng} / \mu \mathrm{L}$ of total DNA, and the ratio of pDD162 to sgRNA to marker pBCN40-R4R3 (plasmid number 34915 on Addgene) was 10:9:1, respectively. Transgenic F1 progeny was screened for mCherry expression and plated individually. After F2 progeny production, F1 animals were screened by single worm PCR and restriction enzyme digestion to identify iglr-2 homozygote mutants.

\section{iglr-2 Transgenic Strain Generation}

To analyze transcription of iglr-2, we PCR amplified the 218 bp region between the start codon of iglr-2 and the $3^{\prime}$ end of the adjacent upstream gene from genomic DNA of wild-type animals. The primers 5'-GGGGACAACTTTGTATAGAAAA GTTGAATTGTTAGATTTTATTTAGATATTATCCTT-3' ${ }^{\prime}$ and 5'-GGGGACTGCTTTTTTGTACAAACTTGTTCTTCTTT TCTTTGTATCAAGACA-3' were used for amplifying the region. This promoter region was constructed to plasmid pCG144 (plasmid number 21376 on Addgene) and pCM5.37 (plasmid number 17253 on Addgene) to destination plasmid pCG150 (plasmid number 17247 on Addgene) generating pWF274 [iglr-2p::mCherry::unc-54 3'UTR] through the Gateway cloning system. Plasmid, pWF237 [iglr-2p::mCherry:: histone H2B::unc-54 3'UTR], was constructed using the same method except that mCherry::histone $\mathrm{H} 2 \mathrm{~B}$ was from pCM1.151 (plasmid number 21386 on Addgene). To analyze the expression of IGLR-2 protein, we PCR-amplified full-length, wild-type iglr-2 coding sequence isoform a (2,322 bp) and isoform $b(1,875 \mathrm{bp})$ from cDNA, respectively and ligated it into the destination plasmid pCG150 via a Gateway cloning method to generate pWF294 [iglr-2p::iglr-2a::mCherry::unc-54 3'UTR] and pWF304 [iglr-2p::iglr-2b::mCherry::unc-54 3'UTR]. The primers (5'GGGGACAAGTTTGTACAAAAAAGCAGGCTATGCGAA AATTTGTATTTTTCGTCGTAG-3') (5'-ACCCTTTGAGAC AGCAGCAGCAGCAGCAGCTCTCTTTTCTGGTGGAGAA TCTG-3') and the primers (5'-GGGGACAAGTTTGTACAAA AAAGCAGGCTATGCGAAAATTTGTATTTTTCGTCGTAG$\left.3^{\prime}\right)$ (5'-ACCCTTTGAGACAGCAGCAGCAGCAGCAGCTTC CTGAAGATGGTAAGTAAGTG-3') were used for amplifying isoform a and isoform $b$, respectively. 


\section{Quantitative RT-PCR}

Assays were carried out as previously described (19). Synchronized populations of wild-type N2 and iglr-2 overexpressed strain animals were grown to the late L4 larval stage and fed with E. coli OP50 or EDL933 for 12 and $24 \mathrm{~h}$ at $20^{\circ}$ C. Total RNA was then extracted using TRI Reagent (Invitrogen) and reverse transcribed with M-MLV reverse transcriptase (Promega) using random hexamer primers. This cDNA was then subjected to qRT-PCR analysis using SYBR green detection on a 7,500 fast real-time PCR system (Applied Biosystems). Relative expression between samples was normalized to the $n h r-23$ as the reference gene. The primers (5'-GCCGAAGATGATGCCGAGAT-3'; 5'-GTCGCA GTGT CAAGAATCCC- $3^{\prime}$ ) were used for $n h r-23$ gene detection, and the primers (5'-TTCTCC GAGATGGTGATTTGG-3'; 5' TTCTCCGAGATGGTGATTTGG-3') were used for iglr-2 gene detection. All experiments were performed a minimum of three times independently.

\section{RNA Interference Plate Assay}

RNAi experiments were performed as described with some modifications (30). In brief, RNAi E. coli strains HT115 transformed with RNAi plasmids were spread on NG-IC plates which are NGM plates with $50 \mu \mathrm{g} / \mathrm{mL}$ carbenicillin and $1 \mathrm{mM}$ isopropyl- $\beta$-D-1-thiogalactopyranoside (IPTG). Plates with RNAi bacteria were incubated at $25^{\circ} \mathrm{C}$ overnight to induce the double-stranded RNA (dsRNA) expression. Synchronized wildtype N2, RNAi-sensitized strain $r r f-3$ (pk1426), and tissue specific RNAi knockdown strains L1 stage larvae were obtained using standard alkaline hypochlorite protocols (24). L1 stage larvae cultured on L4440 or plates expressing RNAi of interest at $20^{\circ} \mathrm{C}$ until F1 progenies grown to L4 stage. Survival assays were conducted by mixing control OP50-GFP or EDL933-GFP (19) (which were carrying an ampicillin resistant plasmid) with RNAi bacteria of 1:1 ratio. Mixed bacteria were spread on NGIC plates (30 $\mu \mathrm{L}$ per plate). Approximately fifty worms were picked to the prepared OP50/EHEC-RNAi plates and scored their survival as mentioned above. E. coli HT115 with L4440, an empty vector, was used as a negative control of RNAi. All experiments were performed a minimum of three times independently. Data represent the sum of animals in multiple experiments in the figures.

\section{Images of Nematodes}

Late L4 to young adult stage of iglr-2 reporter strains were plated on NGM plates with E. coli OP50 at $20^{\circ} \mathrm{C}$ for $12 \mathrm{~h}$. For K08D8.5 GFP expression analysis, late L4 to young adult stage of C. elegans strains with K08D8.5::GFP transgene in wild-type and iglr-2(wf275) background were infected with EHEC at $25^{\circ}$ $\mathrm{C}$ for $8 \mathrm{~h}$, respectively. Animals were then mounted on glass slides with $2 \%$ agarose pads and anesthetized with $25 \mathrm{nM}$ sodium azide $\left(\mathrm{NaN}_{3}\right)$. The fluorescent signal in the nematode was observed by differential interference contrast (DIC) imaging with Nomarski optics and epifluorescence imaging with corresponding filters using a Nikon Eclipse Ti inverted microscope system with DP72 CCD camera. The quantification of K08D8.5::GFP signal was measured by imageJ.

\section{Generation of Double Mutant in iglr-2 Mutant Background}

To generate $n s y$-1(ums8);iglr-2(wf295) double mutant, wild-type N2 male animals were crossed to iglr-2(wf295) hermaphroditic gravid adults. Then, male animals of crossed iglr-2 heterozygotes were picked to mate nsy-1(ums8) hermaphrodites. Their progenies of F2 generation were confirmed for iglr-2(wf295), $n s y$-1(ums8) or $n s y$-1(ums8);iglr-2(wf295) by single worm PCR and restriction fragment length polymorphism. The animal exhibited wild-type genotype of iglr-2(wf295), and nsy-1(ums8) was selected as a control. iglr-2(wf295) was confirmed via using the primers (5'-TCTGAATGGAACTGTAATCC-3'; 5' ATTATCGCGAAGAAT TATGA-3'), and the amplicon was then digested by $E c o R V$ enzyme. nsy-1(ums8) was confirmed via using the primers (5'-CGATTTTGACAAATTGGACT-3'; $5^{\prime}$-AGACAAACAACG TCTGGACT-3'), and the amplicon was then digested by $\mathrm{HpyCH} 4 \mathrm{~V}$ enzyme. nsy-1(ums8) gain-offunction allele was a kind gift from Dr. Pukkila-Worley (31). To generate iglr-2(wf275);K08D8.5::GFP, male animals of SAL144 (32) were mated to iglr-2(wf275) hermaphroditic gravid adults. Their progenies of F2 generation showed GFP expression were isolated and confirmed for iglr-2(wf275) by the method as described above. The animal exhibited wild-type genotype of iglr-2(wf275) was selected as a control. The worm strain, SAL144 pha-1(e2123);denEx22 [K08D8.5::GFP + pha-1 $(+)]$ was a kind gift from Dr. Schwartz (32).

\section{EHEC Infection Assay of RPW-24 Treatment}

The assay was performed as described (33) with slight modifications. Briefly, the RPW-24 agar plates were prepared by adding $5 \mu \mathrm{M}$ of RPW-24 (MCE, catalog number: HYW035409) compounds to $3.5 \mathrm{~cm}$ plates containing of $4 \mathrm{~mL}$ NGM agar. $10 \mu \mathrm{L}$ overnight cultured EHEC bacteria were seeded to these RPW-24 agar plates and incubated for $24 \mathrm{~h}$ at $25^{\circ} \mathrm{C}$. Then, thirty to thirty-five synchronized L4 to young adult staged iglr-2 mutants were placed to RPW-24 agar plates and maintained at $20^{\circ} \mathrm{C}$. NGM agar plates supplemented with $0.5 \%$ DMSO were used as negative controls. Animals were scored daily and considered as dead when nematodes did not respond to touch by platinum wire. Worms that crawled off the plate were scored as censored and were transferred to plates every day throughout the reproductive period. The assay was performed independently for four times.

\section{RESULTS}

\section{RNAi Screening for a Potential C. elegans PRR in EHEC Infection}

To identify potential pattern recognition receptors (PRRs) in C. elegans, we constructed and screened a PRR focused RNAi library. These RNAi clones target 315 genes that encode various PRRs specific motifs or domains (Figure 1A and Table S2). We identified that knockdown of seven genes, including lron-9 $(P<$ $0.05)$, iglr-2 $(P<0.001)$, mog-2 $(P<0.05)$, sds-22 $(P<0.05)$, soc- 2 
A

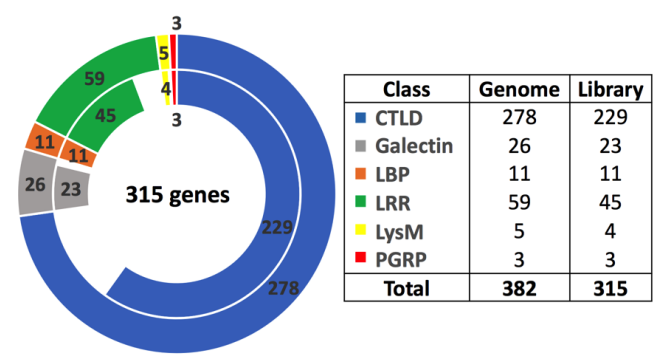

B

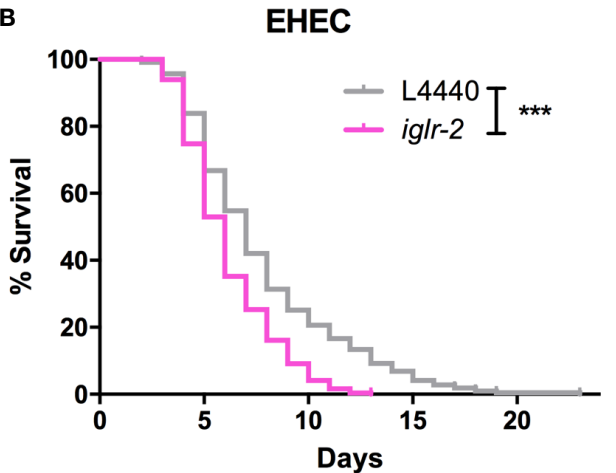

FIGURE 1 | RNAi screening identified iglr-2 is required for host defense in C. elegans. (A) The doughnut chart represents the number of selected genes containing specific proteins/domains that are considered as PRRs and the number of RNAi bacteria clones in RNAi library constructed from Ahringer RNAi library or Worm ORFeome library. The outer ring represents 382 selected genes considered as potential PRRs. The inner ring represents 315 RNAi clones. Sixty-seven genes are deficient in both Ahringer RNAi library or Worm ORFeome library. CTLDs, C-type lectin-like domains; LBP, Lipid binding protein; LRR, Leucine-rich repeat domain; LysM, Lysin motif domain; PGRP, Peptidoglycan recognition protein. (B) Knockdown of iglr-2 by RNAi silencing resulted in N2 animals hypersensitive to $E$. coli O157: H7 strain EDL933 infection compared to that of $L 4440(P<0.001)$. ${ }^{\star \star \star} P<0.001$ by the Mantel-Cox log-rank test. Survival curves represent the sum of animals in multiple experiments.

$(P<0.05)$, pxn-2 $(P<0.05), z m p-2(P<0.001)$, increased susceptibility of animals to EHEC infection when compared to the empty vector, L4440 by one-way ANOVA test. Among them, only iglr-2 RNAi exhibited a significantly decreased survival of EHEC to C. elegans and did not cause developmental defect to compromise our analysis in the adult animals; we therefore turned our focus to analyze the role of iglr-2 during EHEC infection in C. elegans. IGLR-2 is a transmembrane protein with an extracellular leucine-rich repeat domain at the N-terminus, an immunoglobulin-like domain in the center, and a transmembrane domain and an intracellular domain at the C-terminus (Figure 2A). To reconfirm our result from RNAi liquid-toxicity assay, we performed EHEC plate-toxicity assay with RNAi of iglr-2. Indeed, RNAi-mediated knockdown of iglr-2 that targets the leucine-rich repeat (LRR) and immunoglobulin (IG)-like domains in wild-type N2 strain exhibited hypersusceptibility to EHEC (Figure 1B, $P<$ 0.001 by Log-rank test).

\section{Loss of iglr-2 in C. elegans Confers Hypersusceptibility to EHEC Infection}

To strengthen our hypothesis that iglr-2 is required for C. elegans to defend against EHEC O157:H7 strain EDL933 infection, we generated iglr-2 deletion mutants by the clustered regularly interspaced short palindromic repeats and CRISPR-associated protein 9 (CRISPR-Cas9) genome-editing technology (20, 21). We designed single guide RNA (sgRNA) targeting at the LRR domain of $i g l r-2$ and generated two independent mutants (Figure 2A). iglr-2(wf275) mutant had four nucleotides deleted causing a tyrosine to change to a stop codon in codon 284 of the LRR domain by prediction of amino acid sequences. iglr-2(wf295) mutant not only had four nucleotides deleted; it also had one nucleotide changed (Adenosine to Guanosine) and a leading tyrosine changed to a stop codon in codon 284 of the LRR domain as well (Figure 2A). Furthermore, we also designed sgRNA targeting at the transmembrane domain of iglr-2 and generated two independent mutants iglr-2(wf297) had one nucleotide alteration (Thymidine to Adenosine) and seven nucleotide insertion causing a start codon (Methionine) to change to a stop codon in codon 543 of the transmembrane domain by prediction of amino acid sequences. iglr-2(wf298) had one nucleotide deleted also causing a start codon (Methionine) to change to a stop codon in codon 605 of the transmembrane domain (Figure 2B). Svensk et al. revealed that iglr-2 mutant exhibited a withered tail tip defect when grown at $15^{\circ} \mathrm{C}$ for $144 \mathrm{~h}$ (34). Consistent with their findings, we also observed that four of our iglr-2 alleles shared the same withered tail tip defect phenotype at $15^{\circ} \mathrm{C}$ (Figure S2), implying the function of IGLR-2 is disrupted in these mutants. We next examined the susceptibility of these iglr-2 null mutants to EHEC. iglr-2 mutants disrupted either in LRR domain or transmembrane domain were more susceptible to EHEC compared to the wild-type N2 (Figures 2C, D, All $P<0.001$ by Log-rank test). Moreover, the colonization of EHEC in iglr-2(wf275) was significantly increased (Figure S3A), but the defecation cycle and pumping rate were compatible to $\mathrm{N} 2$ (Figures S3B, C), which implied that the increased bacterial accumulation was not contributed by rapid pumping and/or slow defecation in iglr-2(wf275) animals. Taken together, our data indicated that iglr-2 loss-of-function in C. elegans confers animals hypersusceptibility to EHEC infection.

\section{Overexpression of iglr-2 Confers C. elegans Resistance to EHEC}

To examine the relationship between iglr-2 expression and EHEC infection, we detected the change in the expression level of iglr-2 after EHEC infection by qRT-PCR analysis. The data demonstrated that iglr-2 transcript expression level was significantly upregulated after wild-type N2 animals fed on EHEC for either $12 \mathrm{~h}$ post infection (h p.i.) $(P<0.01$ by unpaired t-test) or $24 \mathrm{~h}$ p.i. $(P<0.001$ by unpaired t-test $)$ compared to that of the control OP50 (Figure 3A). These results indicated that iglr-2 is induced upon EHEC infection. 
A

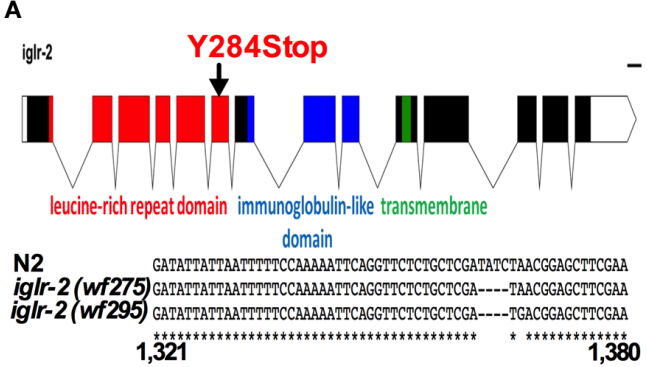

C

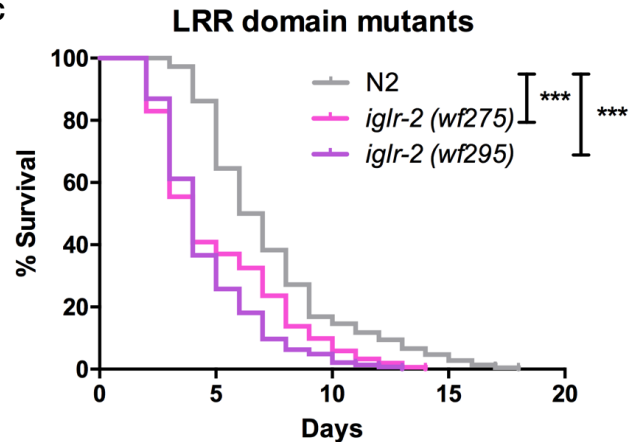

M543Stop

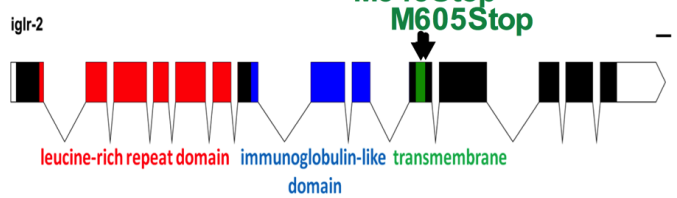

N2 TGGATTCTCACCCGAAAAAGTGCTCTTTGGTGGA-------TTCAAAGGTACC iglr-2 (wf297) TGGATTCTCACCCGAAAAAGTGCTCTTTGGTGGAAAGATCCATCAAAGGTACC iglr-2 (wf298) TGGATTCTCACCCGAAAAAGTGCTCTTTGGTGGA--------TCAAAGGTACC $\begin{array}{ll}*, 768 & 2,827\end{array}$

D
Transmembrane mutants

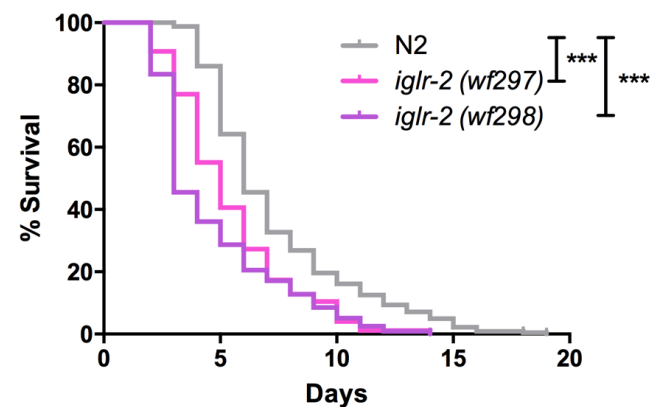

FIGURE 2 | iglr-2 null mutants created by CRISPR-Cas9 genome editing are hypersusceptible to EHEC. (A, B) Top: Diagram of iglr-2 isoform transcript. Position and mutation as indicated. Colored filled boxes are exons. Boxes in red indicate the leucine-rich repeat (LRR) domain region. Boxes in blue indicate immunoglobulinlike (lg-like) domains region. Boxes in green indicate the transmembrane region. Lines are introns. Blank regions are untranslated. Bottom: DNA sequence of iglr-2 mutants compared to N2 wild type. (C) Mutation at LRR domain of iglr-2 contributed C. elegans hypersusceptible to E. coli O157:H7 strain EDL933 infection. [N2 vs iglr-2 (wf275) $P<0.001$, N2 vs iglr-2 (wf295) $P<0.001$ ]. (D) Survival curves of two iglr-2 transmembrane domain mutants fed with EHEC exhibited a significant sensitive phenotype compared to that of $\mathrm{N} 2$ [iglr-2 (wf297) $P<0.001$, iglr-2 (wf298) $P<0.001$ ] animals at $20^{\circ} \mathrm{C}$. ${ }^{\star \star \star} P<0.001$ by the Mantel-Cox log-rank test. Survival curves represent the sum of animals in multiple experiments.

We were then interested in the effect of iglr-2 overexpression in C. elegans. We constructed the iglr-2 expression plasmid with whole iglr-2 sequence and injected the plasmid into wild-type N2 to generate two independent iglr-2 overexpressed strains iglr-2 o/ e-1 (strain YQ322) and iglr-2 o/e-2 (strain YQ323). First, we examined whether the expression level of iglr-2 was elevated in these overexpressed strains by qRT-PCR analysis. Expression level of iglr-2 transcripts in iglr-2 o/e-1 and iglr-2 o/e-2 was significantly enhanced regardless of feeding on OP50 to young adult stage (both of $P<0.001$ by unpaired t-test) or gravid adult stage (both of $P<0.001$ by unpaired t-test) (Figure 3B). Next, we fed N2, iglr-2 o/e-1 and iglr-2 o/e-2 with EHEC to examine their sensitivity to EHEC. The results showed that iglr-2 overexpressed strains were significantly more resistant to EHEC compared to that of N2 (Figure 3C, both $P<0.001$ by Log-rank test). Taken together, our data suggested that iglr-2 plays an important role in protecting C. elegans against EHEC infection.

\section{iglr-2 Is Expressed in Neuronal and Intestinal Cells and May Act in These Tissues to Defend Against EHEC}

In order to determine the expression pattern and identify the site of action of iglr-2, we constructed a plasmid that specifically expresses red fluorescence under the control of the iglr-2 $5^{\prime}$ promoter and injected the plasmid into wild-type animals to generate two independent transcriptional reporter animals iglr$2 p:: m$ Cherry (strain YQ305) and iglr-2p::mCherry::histone H2B (strain YQ326). We fed these two transcriptional reporter strains with E. coli OP50 and examined the expression pattern of red fluorescence at their young adult stage. iglr-2p::mCherry transgenic animals displayed red fluorescence expression in the neurons of the head and anterior/posterior part of the intestinal cells, which suggested that iglr-2 is expressed in these tissues (Figures 4A-I). iglr-2p::mCherry::histone $H 2 B$ transgenic animals also displayed red fluorescence expression pattern resembling iglr-2p::mCherry animals except for the red fluorescent signal only being detected in the nuclei of these tissues (Figures 4J-R). Furthermore, iglr-2p::iglr-2a::mCherry (strain YQ338) and iglr-2p::iglr-2b::mCherry (strain YQ362) animals showed two IGLR-2 protein isoforms, which were also expressed in the neurons of the head and anterior/posterior part of the intestine (Figure S4). To reconfirm the site of action of $i g l r$-2, we used tissue-specific RNA knockdown strains to silence iglr-2 in specific tissues and then examined their survival on EHEC infection. Figure 5A shows the survival curves of iglr-2 silencing in RNAi-sensitized strain $r r f-3(p k 1426)$ resulting in $C$. elegans exhibiting susceptible phenotype to EHEC compared to 
A

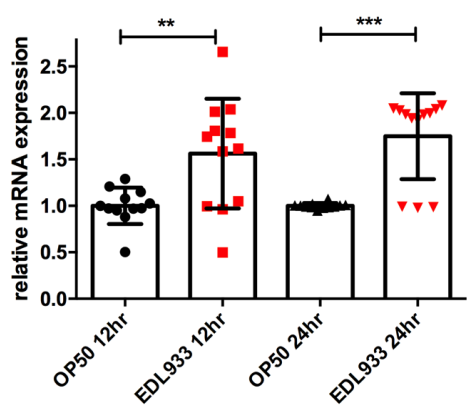

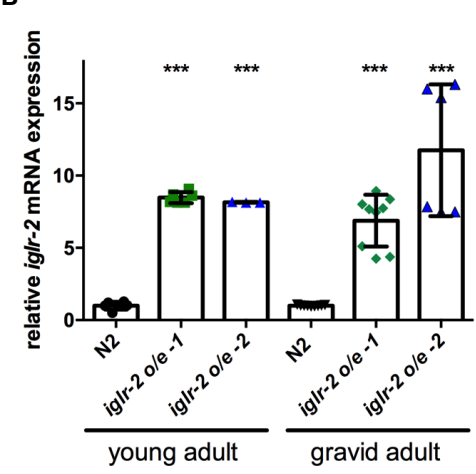

C

\section{EHEC}

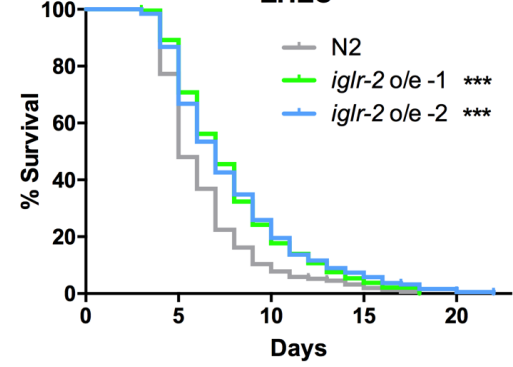

FIGURE 3 | Overexpression of iglr-2 confers C. elegans resistance to EHEC. (A) iglr-2 transcriptional level is significantly up-regulated upon EHEC infection. The iglr2 mRNA expression level of N2 worms infected with $\mathrm{E}$. coli $0157: \mathrm{H} 7$ strain EDL933 at $20^{\circ} \mathrm{C}$ was measured by qRT-PCR analysis at $12 \mathrm{~h}$ p.i (hours post infection) or $24 \mathrm{~h}$ p.i. Results were the average of three biological replicates and were normalized to the expression level of the $n h r-23$ control gene. Expression is relative to $E$. coli OP50. The error bars represent the standard deviation. ${ }^{\star \star} P<0.01$ and ${ }^{\star \star \star} P<0.001$ by the unpaired t-test, respectively. (B) The mRNA expression level of iglr-2 in ig/r-2 overexpressed strains was measured by qRT-PCR analysis. cDNA was extracted from N2 and two overexpressed strains, ig/r-2 o/e-1 and ig/r-2 o/e-2, which were fed with OP50 and grown to young adult stage or gravid adult stage at $20^{\circ} \mathrm{C}$. Results were normalized to the expression level of the nhr-23 control gene. Expression is relative to wild-type N2. ${ }^{\star \star \star} P<0.001$ by the unpaired t-test. (C) Survival curves of two iglr-2 overexpressed strains feeding on EHEC exhibited a significant resistant phenotype compared to that of N2 (ig/r-2 o/e-1 $P<0.001$, ig/r-2 o/e-2 $P<0.001$ ) at $20^{\circ} \mathrm{C}$. ${ }^{\star * \star} P<0.001$ by the Mantel-Cox log-rank test. Survival curves represent the sum of animals in multiple experiments.

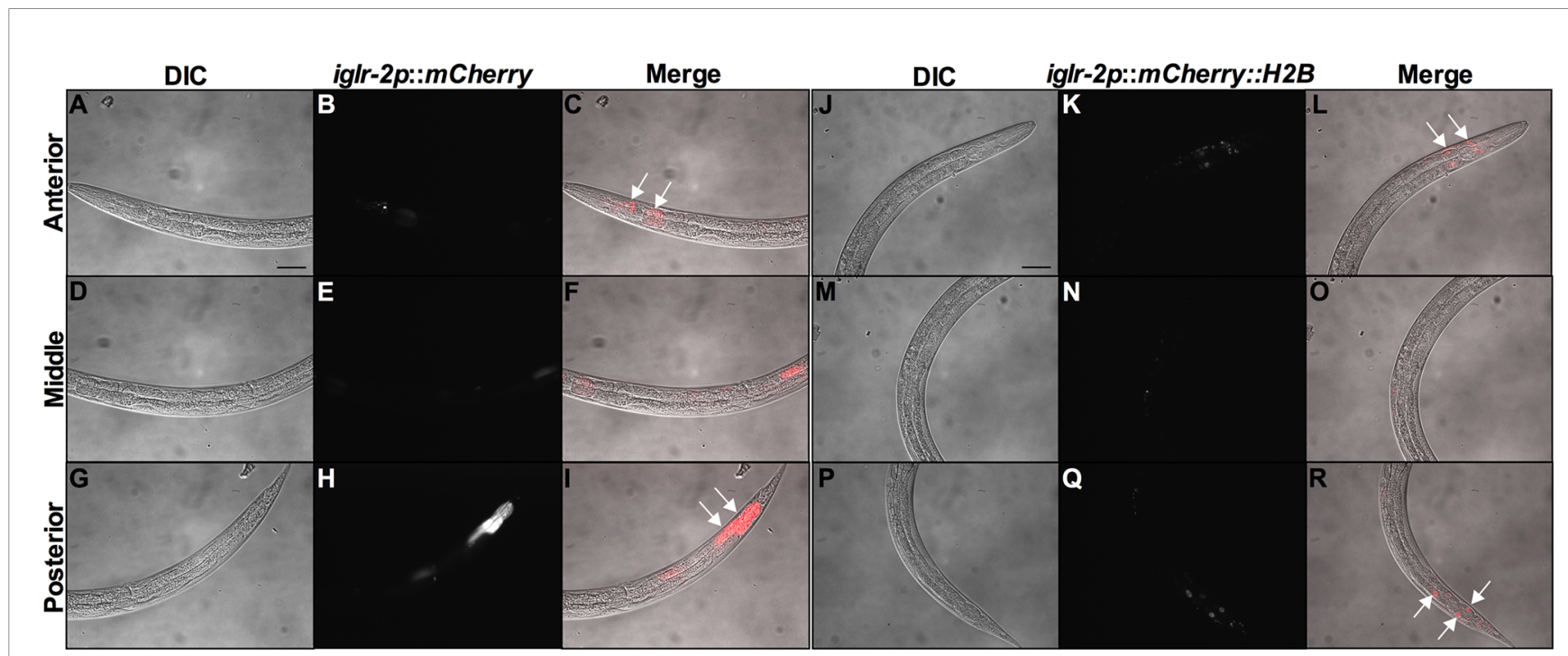

FIGURE 4 | iglr-2 is expressed in neurons and intestine. Fluorescence images show iglr-2p::mCherry or iglr-2p::mCherry::H2B reporter strains exhibiting mCherry fluorescent signal in both neuronal and anterior/posterior intestinal cells at the young adult stage. (A-I) Representative images of YQ305 [ig/r-2p::mCherry] transgenic animals are shown. (A-C) Anterior part of $C$. elegans YQ305 strain is shown. Arrows indicate the neuronal cells of head and anterior part of intestinal cells in (C). (D-F) Middle part of C. elegans YQ305. (G-I) Posterior part of C. elegans YQ305 strain is shown. Arrows indicate the posterior part of intestinal cells in (I). (A, D, G) represent differential interference contrast (DIC) images of the proximal, middle, and distal parts of $C$. elegans, respectively. (B, E, $\mathbf{H})$ mCherry fluorescence images of iglr-2p::mCherry animals. (C, F, I) Merged images of iglr-2p::mCherry animals. (J-R) Representative images of YQ326 [iglr-2p::mCherry::H2B] transgenic animals are shown. (J-L) Anterior part of $C$. elegans YQ326 strain is shown. Arrows indicate the neuronal nuclei of head and anterior part of intestinal nuclei in (L). (M-O) Middle part of C. elegans YQ326. (P-R) Posterior part of C. elegans YQ326 strain is shown. Arrows indicate the posterior part of intestinal nuclei in (R). (J, M, P) represent differential interference contrast (DIC) images of the proximal, middle, and distal parts of $\mathbf{C}$. elegans, respectively. (K, $\mathbf{N}, \mathbf{Q}) \mathrm{mCherry} \mathrm{fluorescence} \mathrm{images} \mathrm{of} \mathrm{iglr-2p::}$ mCherry animals. (L, $\mathbf{O}, \mathbf{R})$ Merged images of iglr-2p::mCherry animals. All the scale bars represent $50 \mu \mathrm{m}$.

that of empty vector control, L4440 ( $P<0.001$ by Log-rank test). Similar results are shown in Figures 5B, C; when knockdown of iglr-2 was specific to neurons or the intestine in worms, they were significantly more susceptible to EHEC $(P<0.001$ by Log-rank test). However, specific knockdown of iglr-2 in the muscle did not alter the susceptibility of animals to EHEC compared to the empty vector control (Figure 5D, $P=0.3725$ by Log-rank test). These data are consistent with the images (Figure 4) that show 
that iglr-2 is only expressed in the neurons and the intestines. Taken together, these data suggested that iglr-2 plays a role in the neural system and intestine to defend against EHEC.

\section{iglr-2 Is Required for Behavioral Avoidance of EHEC}

We noticed that part of the iglr-2 signal appears in the neurons (Figure 4 and Figure S4). In the C. elegans nervous system, the olfactory nerve has been reported to play an important role in detecting pathogens and to mediate host-pathogen interactions through chemosensation (29). C. elegans is attracted by most bacteria, but some pathogens like $P$. aeruginosa stimulate $C$. elegans to avoid them (35). We demonstrated that the iglr-2 expression was located with neurons in the head and tail (Figure 4 and Figure S4). Therefore, we hypothesize that iglr-2 may be involved in avoidance behavior to EHEC. We transferred N2, iglr-2 mutant and iglr-2 overexpressed worms to the plates containing bacterial lawn and scored the occupancy of animals on the bacterial lawn after keeping them at $20^{\circ} \mathrm{C}$ for $16 \mathrm{~h}$. The occupancy index was calculated as the number of animals on the bacterial lawn divided by the total number of animals on plates. Indeed, loss of iglr-2 resulted in more animals lingering on OP50
$(P<0.001$ by unpaired $t$-test $)$ or EHEC $(P<0.001$ by unpaired $t-$ test) bacterial lawn compared to that of wild-type N2 animals (Figures 6A, B). Overexpression of iglr-2 reversed the avoidance behavior, which was similar to wild-type N2 on either the OP50 or EHEC bacterial lawn (Figures 6A, B). Of note, iglr-2 deficiency animals exhibited similar avoidance behavior to $P$. aeruginosa PA14 compared to that of wild-type N2 (Figure 6C, $\mathrm{P}=0.14$ by unpaired t-test), which suggested that iglr-2 showed selectivity to $E$. coli and was not involved in the avoidance behavior to $P$. aeruginosa in C. elegans. Taking these results together, we demonstrated that iglr-2 is required for behavioral avoidance to pathogenic E. coli, EHEC, and the relatively weak pathogen, E. coli OP50 (36) in C. elegans. P. aeruginosa PA14 is considered an acute pathogen to C. elegans which kills animals within one day (37). We noticed that animals on PA14 bacterial lawn showed a low percentage $(\sim 0 \%)$ of occupancy for exposing $16 \mathrm{~h}$. To test whether the fast killing of PA14 may hinder the potential increased avoidance of animals, we reduced the assay time of avoidance behavior experiment. We first scored the occupancy index of N2 animals on PA14 in a time-dependent manner. The occupancy of N2 on PA14 was approximately $40 \%$ for $8 \mathrm{~h}$ exposure and was dropped to $10 \%$ for $12 \mathrm{~h}$ (Figure S5). We then measured the occupancy of iglr-2
A

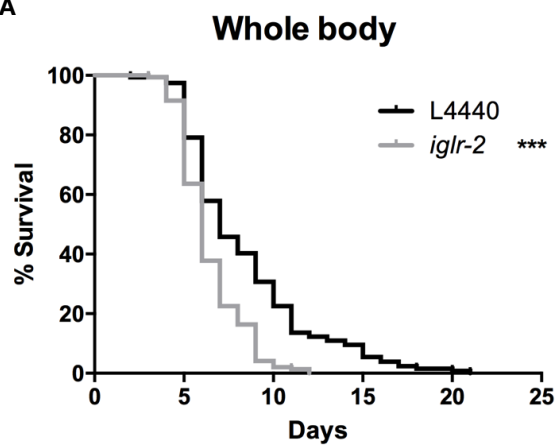

C

Intestine

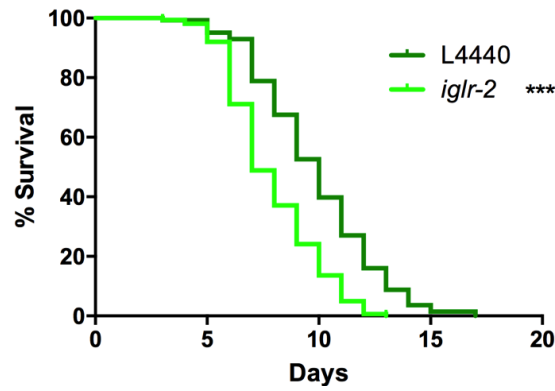

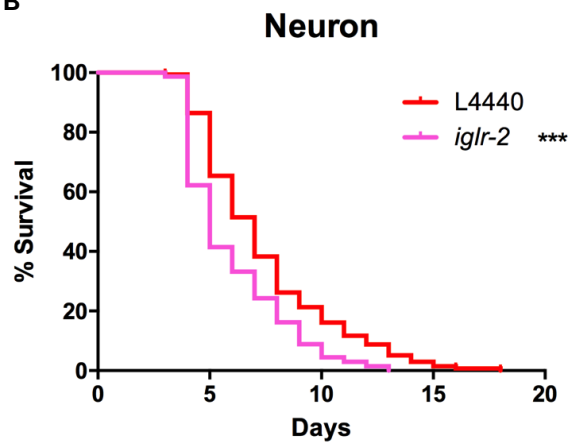

D

Muscle

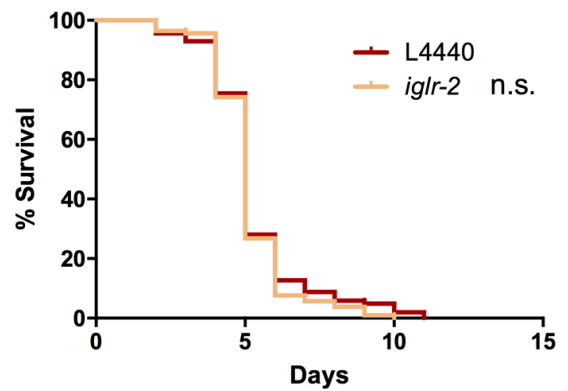

FIGURE 5 | iglr-2 may act in the neuron and intestine to defend against EHEC. (A) Survival curve of RNAi-sensitized strain NL2099 rrf-3(pk1426) showed that iglr-2 silencing in whole-body cell resulted in C. elegans being more sensitive to EHEC infection compared to that of empty vector $L 4440$ control $(P<0.001)$. (B) Survival curve of neuron-specific RNA knockdown strains TU3401 showed that iglr-2 silencing in neuron cells resulted in C. elegans is more sensitive to EHEC compared to that of empty vector $L 4440(P<0.001)$. (C) Survival curve of intestine-specific RNAi knockdown strain VP303 showed iglr-2 silencing in intestine cells resulted in C. elegans being more sensitive to EHEC infection compared to that of empty vector $L 4440$ control $(P<0.001)$. (D) Specific knockdown of iglr-2 in muscle cells by muscle-specific RNAi knockdown strain WM118 showed a similar survival curve compared to that of empty vector $L 4440$ control to EHEC infection $(P=0.3725)$. ${ }^{\star \star *} P<0.001$ by the Mantel-Cox log-rank test. Survival curves represent the sum of animals in multiple experiments. 
A

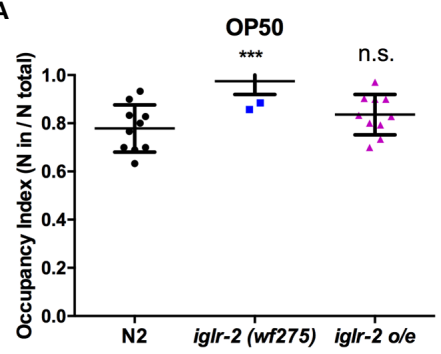

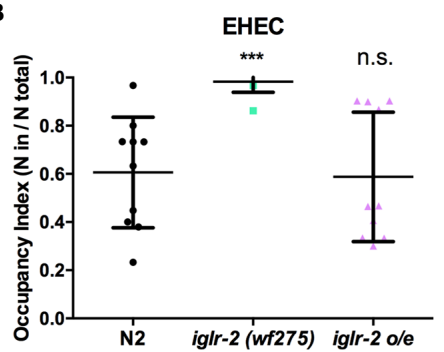

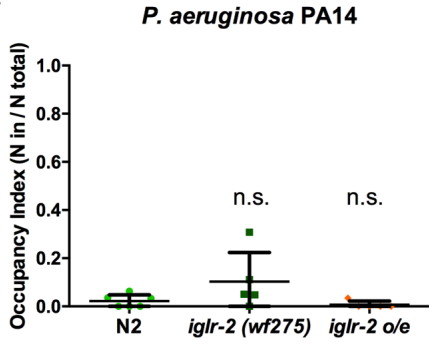

FIGURE 6 | ig/r-2 is required for bacterial avoidance behavior to EHEC. (A) Occupancy index of wild-type N2, iglr-2 mutants, and iglr-2 overexpressed strains on E. coli OP50 bacterial lawn for $16 \mathrm{~h}$ was analyzed. iglr-2 mutant strain lost the ability to avoid OP50 compared to that of wild-type N2 by unpaired t-test (***, N2 vs. iglr-2 (wf275), $P<0.001$, N2 vs iglr-2 o/e-1 $P=0.173$ ). (B) Occupancy index of wild-type N2, iglr-2 mutants and iglr-2 overexpressed strains on EHEC bacterial lawn for $16 \mathrm{~h}$ was scored. iglr-2 mutants displayed higher occupancy on EHEC compared to that of wild-type N2 by unpaired t-test. ${ }^{\star \star \star}$ indicates N2 vs. iglr-2 (wf275) $P<0.001$ and ns (no significance) indicates N2 vs iglr-2 o/e-1 $P=0.871$. (C) Occupancy index of wild-type N2, iglr-2 mutants, and iglr-2 overexpressed strains on $P$. aeruginosa PA14 bacterial lawn for $16 \mathrm{~h}$ was scored. iglr-2 mutants and overexpressed strain showed a similar avoidance behavior index compared to that of wild-type N2 by unpaired t-test [iglr-2 (wf275) $P=0.140$, iglr-2 o/e-1 $P=0.289$ ]. ns indicates no significance. Each experiment conducted on three biological replicates, and results were the average of experimental replicates. Error bars represent SD.

mutant on PA14 for 8-h treatment and found that iglr-2(wf275) exhibited a comparable aversion behavior compared to N2 (Figure S6, $\mathrm{P}=0.15$ by unpaired t-test), suggesting that the occupancy assay might not be affected by fast killing of PA14.

\section{p38 MAPK Pathway Acts Downstream of iglr-2}

Next, we aimed to identify the downstream signal of iglr-2. TOL1, MOM-4, and PMK-3 function together in a signaling pathway in the chemosensory BAG neurons (29). Therefore, we were interested in whether the TLR signaling pathway is also involved in iglr-2 protecting hosts from death by EHEC in C. elegans. We performed RNAi-mediated knockdown of mom-4 in iglr-2 overexpressed animals (iglr-2 o/e, YQ322) upon infecting EHEC. Survival of iglr-2 o/e with RNAi silencing of mom-4, a MAP kinase kinase kinase (MAP3Ks), in TLR signaling, was comparable to that of the empty vector control L4440 (Figure S7, $\mathrm{P}=0.44$ by Log-rank test), which suggested that the MAP3Kinvolved TLR signals are not the downstream signaling pathway of iglr-2 in C. elegans. Several evolutionarily conserved innate immune responses have been reported to be involved in defending pathogenic microbes in C. elegans, for example, the insulin-like signaling pathway (38), the unfolded protein response (UPR) signaling pathway (38), the autophagy pathway (39), and the p38 MAPK pathway (38). We therefore tested these known innate immune pathways in C. elegans to determine whether these pathways are involved in the iglr-2mediated defense system against EHEC. When insulin-like signaling pathway DAF-16/FOXO transcriptional factor, daf16, was knocked down by RNAi-mediated silencing in iglr-2 o/ e, no significant difference was observed in the survival compared to empty vector, L4440 control (Figure S8A, P = 0.14 by Logrank test). Similar results were also found when $x b p-1$ was knocked down in iglr-2 o/e, which is spliced by IRE-1 during endoplasmic reticulum (ER) stress to activate UPR. The survival was compatible to the L4440 control (Figure S8B, $P=0.24$ by Log-rank test). Knockdown of a helix-loop-helix transcription factor regulating autophagy gene expression, TFEB/hlh-30, in iglr-2 o/e C. elegans resulted in slightly enhanced sensitivity compared to the control (Figure S8C, $P<0.05$ by Log-rank test). Our previous study demonstrated that the p38 MAPK pathway is activated in C. elegans for defending EHEC infection (19). To determine whether the p38 MAPK pathway is involved in iglr-2 regulating immune response, we examined the survival of iglr-2 o/e strain silencing of genes involved in p38 MAPK pathway upon EHEC infection. iglr-2 o/e subjected to pmk-1 RNAi was significantly susceptible to EHEC compared to the empty vector control, L4440 (Figure 7A, $P<0.001$ by Log-rank test). Consistently, RNAi knockdown of $n s y-1$, tir-1 and sek-1 suppressed the extended survival of $i g l r-2$ o/e to EHEC, respectively (Figures S9A-C). Furthermore, survival of RNAi against pmk-1 to iglr-2(wf275) was compatible to that of control (Figure 7B, $P=0.22$ by Log-rank test), suggesting iglr-2 and pmk-1 act in the same pathway to defend EHEC in C. elegans. Together, these data indicated that the p38 MAPK signaling cascades act downstream of iglr-2. To further reconfirm the notion that the p38 MAPK signaling cascades act downstream of $i g l r-2$, we performed genetic epistasis analysis using a $n s y-1$ gainof-function allele, $n s y$-1(ums8), which constitutively activates the p38 MAPK cascades (31). We generated nsy-1(ums8);iglr-2 (wf295) double mutant and examined its survival to EHEC. As shown in Figure 7C, hyperactivation of p38 MAPK pathway in iglr-2(wf295) significantly increased the survival of iglr-2 mutant animals to EHEC infection. Moreover, $n s y$-1(ums8);iglr-2(wf295) animals were more susceptible to EHEC infection compared to $n s y$-1 (ums 8$)(P<0.001$ by Log-rank test), and the survival curve of $n s y$-1(ums8);iglr-2(wf295) was similar to that of wild-type (WT) animals $(P=0.835$ by Log-rank test). These results reconfirm that the iglr-2, at least partly, regulated the p38 MAPK pathway. An alternative explanation of this result is that p38 MAPK pathway hyperactivation also induces aversion 


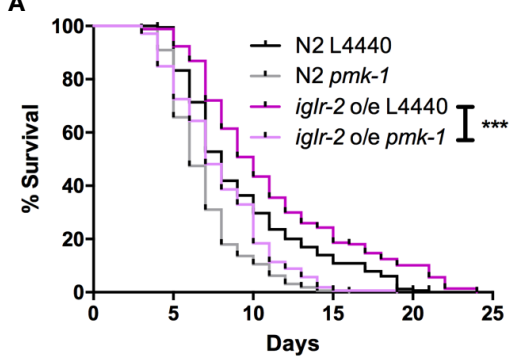

D

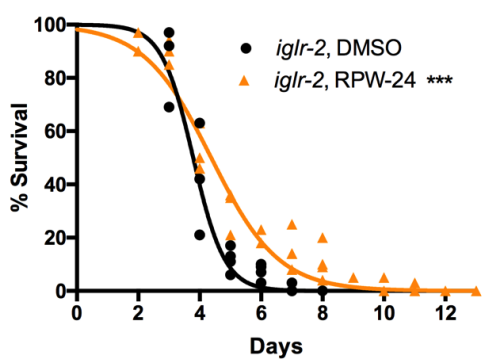

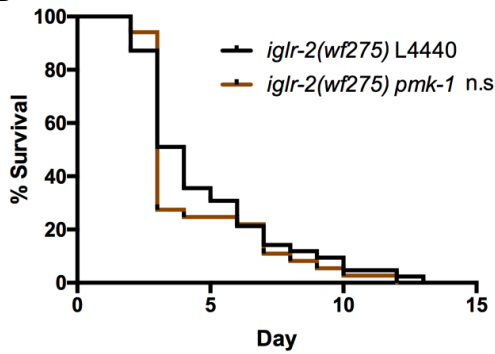

E

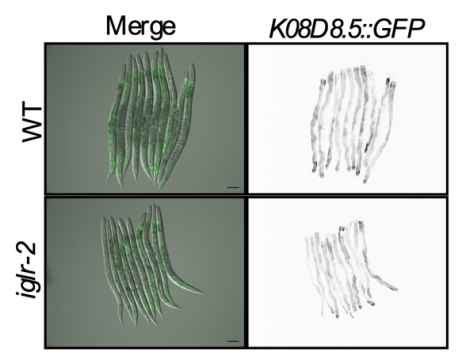

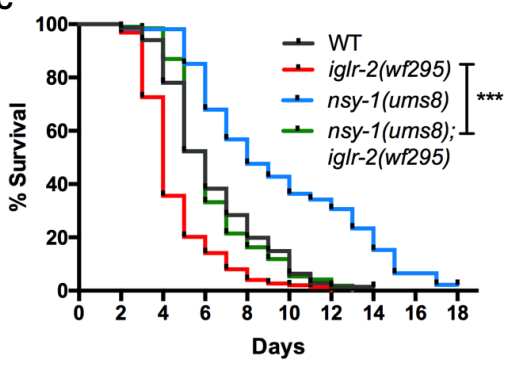

$\mathbf{F}$

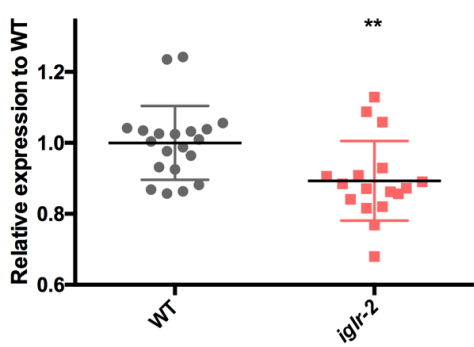

FIGURE 7 | PMK-1 p38 mitogen-activated protein kinase (MAPK) pathway acts as downstream signal of iglr-2. (A) RNAi-mediated knockdown of pmk-1 in iglr-2 overexpressed animal resulted in hypersusceptibility to EHEC compared to empty vector control, L4440 $(P<0.001)$. ${ }^{* \star *} P<0.001$ by the Mantel-Cox log-rank test. (B) Survival curves of iglr-2 mutant RNAi against pmk-1 were comparable to EHEC compared to empty vector control, L4440 (P=0.22) (C) Survival of $n s y-1$ (ums8) gain-of-function allele and iglr-2(wf295) double mutant strain infected with EHEC at $20^{\circ} \mathrm{C}$ was examined. $n s y-1$ (ums8);iglr-2(wf295) animals lived longer than iglr-2 (wf295) $(P<0.0001)$ when fed with EHEC at $20^{\circ} \mathrm{C}$ but exhibited a similar survival compared to that of wild-type (WT) worms $(P=0.835)$. nsy-1 (ums8) gain-offunction strain was significantly resistant to EHEC infection compared to that of WT $(P<0.001)$. ${ }^{* \star} P<0.001$ by the Mantel-Cox log-rank test. (D) Survival analysis of iglr-2(wf295) supplemented with 5 MM RPW-24 upon EHEC infection at $20^{\circ} \mathrm{C}$ was examined. Treatment of RPW-24 increased the survival of iglr-2(wf295) animals compared to that of DMSO control. $(P<0.001)$. Survival curves represent the sum of animals in multiple experiments. (E) Representative images of K08D8.5::GFP transgenic animals infected with EHEC were shown. K08D8.5::GFP wild type and iglr-2 mutant background worms were treated with EHEC for $8 \mathrm{~h}$ and imaged. Merged images indicate GFP overlaid with DIC. GFP images are presented inverted signal of GFP. Scale bars represent $100 \mu \mathrm{m}$. (F) Relative fluorescence expression of K08D8.5::GFP transgenic worms infected with EHEC for $8 \mathrm{~h}$. Each dot represents the relative GFP expression of single animal to the mean of wildtype control. ${ }^{\star \star} P<0.01$ by the unpaired t-test. Error bars represent SD.

behavior of C. elegans to EHEC, and disruption of iglr-2 suppresses the behavior contributing $n s y$-1(ums8);iglr-2(wf295) susceptible to EHEC. However, we found that $n s y$-1(ums8) did not escape from EHEC infection, and iglr-2 loss of function in $n s y$-1 (ums8) animal exhibited a compatible aversion behavior to iglr-2(wf295) and $n s y$-1(ums8) (Figure S10), suggesting that suppression of the increased EHEC resistance in $n s y$-1(ums8); iglr-2(wf295) was not due to the absence of aversion behavior from iglr-2 loss of function. In addition to activate the p38 MAPK immune pathway in the iglr-2 mutant genetically, we also induced the p38 MAPK pathway pharmacologically to strengthen our hypothesis. RPW-24, a small molecule drug, had been reported to stimulate immune genes through p38 MAPK pathway in C. elegans (33). We therefore supplemented RPW-24 to iglr-2 mutant worms upon EHEC infection and examined the survival. Treatment of $5 \mu \mathrm{M}$ of RPW-24 increased the survival of iglr-2 mutant animals against EHEC compared to the vehicle control (Figure 7D, $P<0.001$ ). An interpretation of this result is that RPW-24 may directly inhibit or kill EHEC bacteria. However, EHEC treated with $5 \mu \mathrm{M}$ RPW24 exhibited similar growth curves to untreated control (Figure
S11) suggesting that treatment of RPW-24 did not affect the growth of EHEC. Next, we asked whether the expression of p38 MAP kinase-dependent genes is changed in iglr-2 mutant. We examined the GFP expression of K08D8.5::GFP strain, a gene that encoded CUB-like domain regulated by the p38 MAPK signaling (32), under iglr-2(wf275) background. The expression pattern of K08D8.5::GFP was throughout the intestine of the worms extensively while subjected to EHEC (Figure 7E). In contrast, iglr-2(wf275);K08D8.5::GFP strain showed a significant reduction of GFP level to wild-type control (Figures 7E, F, $P<$ 0.01 ). These results indicated that iglr-2 is involved in the regulation of p38 MAPK-dependent gene. It did not escape our attention that iglr-2 had been reported to regulate NHR-49 (34) (ortholog of the mammalian nuclear-hormone receptor $\operatorname{PPAR} \alpha$ ), which is correlated with $C$. elegans' immune response $(40,41)$. We then examined the susceptibility of iglr-2 o/e $C$. elegans RNAi knockeddown of $n h r-49$ to EHEC infection. iglr-2 o/e treated with $n h r-49$ RNAi lived significantly shorter than the control (Figure S12, $P<0.001$ ), suggesting that $n h r-49$ might be one of the downstream of iglr-2 in C. elegans defending EHEC. All together, our results demonstrated that iglr-2 is required for 
the host defense in Caenorhabditis elegans, at least in part, through the p38 MAPK immune pathway.

\section{DISCUSSION AND CONCLUSIONS}

In this study, we identified that a membrane protein, IGLR-2, containing a leucine-rich repeat (LRR) domain, is required for host defense in C. elegans. Our genetic analysis demonstrated that loss of iglr-2 conferred susceptibility of C. elegans to EHEC infection, and overexpression of iglr- 2 contributed to animal host resistance to EHEC. iglr-2 was also required for avoidance behavior to EHEC infection. Moreover, we demonstrated that iglr-2 might act in neural and intestinal tissues and be involved in regulating p38 MAPK pathway activation, partly as a downstream immune response to protect C. elegans from EHEC death (Figure 8). IGLR-2 has been reported to be a plasma membrane sensor interacting with PAQR-2 protein regulating the membrane fluidity by promoting fatty acid desaturation to respond to decreased fluidity during cold adaptation or a diet rich in saturated fatty acids $(34,42,43)$. Here, we report our knowledge for the first time that iglr-2 takes part in response to pathogen infection.

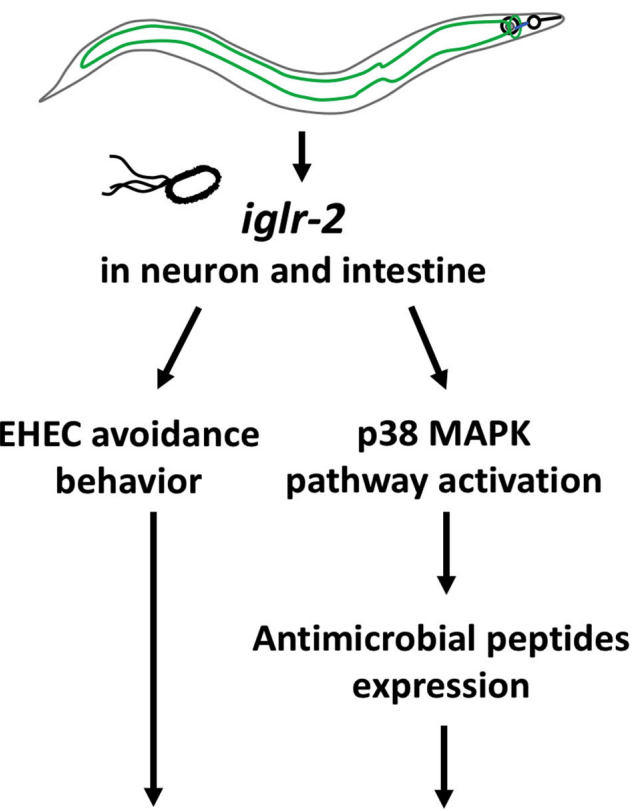

\section{Protect C. elegans from EHEC killing}

FIGURE 8 | Model graphic of iglr-2 defense against EHEC in C. elegans. IGLR-2, an transmembrane protein containing immunoglobulin-like and leucine rich repeat domains, is involved in C. elegans' avoidance behavior to EHEC and triggering downstream p38 MAPK pathway which might function in neuronal cell and intestinal cell.
In our PRR RNAi library screening, we identified seven potential genes (mog-2, soc-2, pxn-2, sds-22, lron-9, zmp-2, and iglr-2) involved in C. elegans against EHEC. $\operatorname{mog}-2$ encodes a U2 snRNP protein and is involved in sex determination, meiosis, and splice site selection in C. elegans (44). soc-2 encodes a leucine-rich repeat protein, which is involved in the fibroblast growth factor receptor signaling pathway and is positively regulated by let-60/Ras and negatively regulated by egl-15/FGF (FGF receptor) in development $(45,46)$. pxn-2 encodes peroxidasin (a family of extracellular peroxidases) which is essential for embryonic morphogenesis in C. elegans (47). sds22 is a phosphatase regulator gene, and loss of $s d s-22$ causes embryonic lethality in C. elegans $(48,49)$. lron-9 is predicted as a glycoprotein that contains an extracellular leucine-repeat and transmembrane region, which is expressed at the head neuron, muscles, and seam cells, and knockdown of lron-9 by RNAi leads to developmental defect in worms $(50,51)$. ZMP-2 is a zinc metalloproteinase which is responsible for development and pathogen resistance in C. elegans (52). Of note, $z m p-2$ was reported having an immune related function, which strengthens the reliability of our PRR RNAi library screening. Nevertheless, further research of the other five genes ( $m o g-2$, soc2, $p x n-2, s d s-22$ and lron-9) in immune regulation is warranted.

We noticed that the iglr-2 expression pattern of our transgenic animals is distinct from the previous research (34). One plausible interpretation is that the promoter region used here is different from the previous one. The mrps-18A gene is adjacent to the promoter of $i g l r-2$. Svensk et al. used the region of $\sim 4 \mathrm{~kb}$ upstream of iglr-2 as an iglr-2 promoter also includes the upstream operon gene, mrps-18A (34). To avoid the effect of mrps-18A, we only cloned the $218 \mathrm{bp}$ fragment from the end of the $3^{\prime}$ untranslated region (UTR) of $m r p s-18 A$ to the start site of iglr-2 as the iglr-2 $5^{\prime}$ $\mathrm{UTR} /$ promoter for our iglr-2 transgene. Another potential explanation is the operation of different $3^{\prime} \mathrm{UTR}$, in which we chose $u n c-54$ for our construct, even though the use of unc-54 $3^{\prime}$ UTR for a transgene is concerned with an artificial expression signal in the posterior of the intestine in C. elegans (53). Nevertheless, we not only observed the mCherry signals in the posterior intestine but also in the anterior intestine and neurons. These results suggested that the mCherry signals are less likely to be the artifacts as the consequence of using the unc-54 3' UTR.

C. elegans animals with iglr-2 mutation occupied the EHEC bacterial lawn longer than N2 but showed similar occupancy to N2 on $P$. aeruginosa bacterial lawn (Figure 6). These data indicate that mutation of iglr-2 does not affect the function of neuron or muscle to abolish the movement in $C$. elegans, but that iglr-2 gene is specific for triggering $C$. elegans host avoidance behavior to minimize EHEC killing. In other words, C. elegans is able to distinguish different pathogens, initiating a unique response to protect itself from pathogen attack. TOL- 1 is the sole toll-like receptor homolog in C. elegans. Currently, TOL-1 does not appear to participate in regulating canonical immune response but plays a role in behavioral avoidance of pathogens (29). tol-1 mutants are defective in the terminal differentiation and function of the BAG neurons which are necessary for chemosensitivity to $\mathrm{CO}_{2}$, resulting in their pathogen-avoidance behavior (54). Although iglr-2 is also involved in pathogen-avoidance behavior, no 
evidence suggests that iglr-2 is involved in neuron differentiation and function; however, whether iglr-2 mutants are defective in sensing $\mathrm{CO}_{2}$ warrants examination. Furthermore, tol-1 seems not to trigger the innate immune pathway according to current studies $(54,55)$. Based on our epistasis results (Figure 7), we found that p38 MAPK pathway, at least in part, is involved in the downstream of iglr-2 against EHEC infection, implying that iglr2 might be a potential PRR in C. elegans.

A recent study showed that a novel protein, CgLRRIG-3, which contains leucine-rich repeat (LRR) and immunoglobulin-like (Ig) domains, plays a crucial role in regulating immune response in oyster, Crassostrea gigas (56). CgLRRIG-3 can bind to lipopolysaccharide (LPS), peptidoglycan (PGN), glucan (GLU), and polyinosinic:polycytidylic acid (poly I:C) to stimulate cytokine expression and enhance the phagocytosis rate of the hemocytes in Crassostrea gigas. This research revealed that the proteins containing leucine-rich repeat (LRR) and immunoglobulin-like (Ig) domains have unidentified functions in immune response in invertebrates. Taken together our findings expand understanding of how C. elegans mounts immune response upon facing pathogens and also advance our current knowledge about evolutionarily conserved strategies in invertebrates.

\section{DATA AVAILABILITY STATEMENT}

The original contributions presented in the study are included in the article/Supplementary Material. Further inquiries can be directed to the corresponding authors.

\section{ETHICS STATEMENT}

Ethical review and approval was not required for the animal study because the authors used C. elegans, the nematode as an animal model, which is not required ethical review and approval for study.

\section{REFERENCES}

1. Stuart LM, Paquette N, Boyer L. Effector-triggered versus pattern-triggered immunity: how animals sense pathogens. Nat Rev Immunol (2013) 13(3):199206. doi: $10.1038 /$ nri3398

2. Mogensen TH. Pathogen recognition and inflammatory signaling in innate immune defenses. Clin Microbiol Rev (2009) 22(2):240-73. doi: 10.1128/CMR.00046-08

3. Aballay A DE, Hilbun LR, Ausubel FM. Caenorhabditis elegans Innate Immune Response Triggered by Salmonella enterica Requires Intact LPS and Is Mediated by a MAPK Signaling Pathway. Curr Biol (2003) 13(1, 8):4752. doi: 10.1016/S0960-9822(02)01396-9

4. Schulenburg H KC, Ewbank JJ. Evolution of the innate immune system: the worm perspective. Immunol Rev (2004) 198:36-58. doi: 10.1111/j.01052896.2004.0125.x

5. Twumasi-Boateng K, Shapira M. Dissociation of immune responses from pathogen colonization supports pattern recognition in C. elegans. PLoS One (2012) 7(4):e35400. doi: 10.1371/journal.pone.0035400

6. Pukkila-Worley R, Ausubel FM, Mylonakis E. Candida albicans infection of Caenorhabditis elegans induces antifungal immune defenses. PLoS Pathog (2011) 7(6):e1002074. doi: 10.1371/journal.ppat.1002074

\section{AUTHOR CONTRIBUTIONS}

Conceived and designed the experiments: C-JK and C-SC. Performed the experiments: C-JK, B-YL, Y-CH, SL, and S-TW. Analyzed the data: C-JK, B-YL, Y-CH, SL, Y-WC, S-TW, and C-SC. Contributed reagents/materials/analysis tools: C-JK, B-YL, Y-CH, SL, and S-TW. Wrote the paper: C-JK and C-SC. All authors contributed to the article and approved the submitted version.

\section{FUNDING}

This work is supported by the Ministry of Science and Technology (MOST) grants (106-2321-B-006-005- and 1072628-B-006-003-) to C-SC. The funders had no role in the study design, data collection, and analysis, decision to publish, or preparation of the manuscript.

\section{ACKNOWLEDGMENTS}

We are grateful for the assistance from the Taiwan C. elegans core facility, funded by the Ministry of Science and Technology (MOST) Taiwan, and feedback from the Taiwan worm research community. We thank the Caenorhabditis Genetics Center (CGC), which is supported by the National Institutes of Health (United States), Office of Research Infrastructure Programs (P40 OD010440), for the C. elegans strains. We are grateful to Dr. Pukkila-Worley for the $n s y$-1(ums8) animal. We thank Miranda Loney for editing the manuscript.

\section{SUPPLEMENTARY MATERIAL}

The Supplementary Material for this article can be found online at: https://www.frontiersin.org/articles/10.3389/fimmu.2020. 561337/full\#supplementary-material

7. Irazoqui JE, Troemel ER, Feinbaum RL, Luhachack LG, Cezairliyan BO, Ausubel FM. Distinct pathogenesis and host responses during infection of C. elegans by P. aeruginosa and S. aureus. PLoS Pathog (2010) 6:e1000982. doi: 10.1371/journal.ppat.1000982

8. Wong D, Bazopoulou D, Pujol N, Tavernarakis N, Ewbank JJ. Genome-wide investigation reveals pathogen-specific and shared signatures in the response of Caenorhabditis elegans to infection. Genome Biol (2007) 8(9):R194. doi: 10.1186/gb-2007-8-9-r194

9. Engelmann I, Griffon A, Tichit L, Montanana-Sanchis F, Wang G, Reinke V, et al. A comprehensive analysis of gene expression changes provoked by bacterial and fungal infection in C. elegans. PLoS One (2011) 6(5):e19055. doi: 10.1371/journal.pone.0019055

10. Williams A, Heider F, Messling J, Rieckher M, Bloch W, Schumacher B. Restoration of Proteostasis in the Endoplasmic Reticulum Reverses an Inflammation-Like Response to Cytoplasmic DNA in Caenorhabditis elegans. Genetics (2019) 212(4):1259-78. doi: 10.1101/440883

11. Sowa JN, Jiang H, Somasundaram L, Tecle E, Xu G, Wang D, et al. The Caenorhabditis elegans RIG-I Homolog DRH-1 Mediates the Intracellular Pathogen Response upon Viral Infection. J Virol (2020) 94(2):1-19. doi: 10.1128/JVI.01173-19 
12. Valanne S, Wang JH, Ramet M. The Drosophila Toll signaling pathway. J Immunol (2011) 186(2):649-56. doi: 10.4049/jimmunol.1002302

13. Ohto U, Tanji H, Shimizu T. Structure and function of toll-like receptor 8. Microbes Infect (2014) 16(4):273-82. doi: 10.1016/j.micinf.2014.01.007

14. Vaure C, Liu Y. A comparative review of toll-like receptor 4 expression and functionality in different animal species. Front Immunol (2014) 5:316. doi: 10.3389/fimmu.2014.00316

15. Kim YK, Shin JS, Nahm MH. NOD-Like Receptors in Infection, Immunity, and Diseases. Yonsei Med J (2016) 57(1):5-14. doi: 10.3349/ymj.2016.57.1.5

16. Zhong Y, Kinio A, Saleh M. Functions of NOD-Like Receptors in Human Diseases. Front Immunol (2013) 4(333):1-18. doi: 10.3389/fimmu.2013.00333

17. Boller T, Felix G. A renaissance of elicitors: perception of microbe-associated molecular patterns and danger signals by pattern-recognition receptors. Annu Rev Plant Biol (2009) 60:379-406. doi: 10.1146/annurev.arplant.57.032905.105346

18. He Y, Zhou J, Shan L, Meng X. Plant cell surface receptor-mediated signaling a common theme amid diversity. J Cell Sci (2018) 131(2):1-11. doi: 10.1242/ jcs. 209353

19. Chou TC, Chiu HC, Kuo CJ, Wu CM, Syu WJ, Chiu WT, et al. Enterohaemorrhagic Escherichia coli O157:H7 Shiga-like toxin 1 is required for full pathogenicity and activation of the p38 mitogen-activated protein kinase pathway in Caenorhabditis elegans. Cell Microbiol (2013) 15 (1):82-97. doi: $10.1111 / \mathrm{cmi} .12030$

20. Friedland AE, Tzur YB, Esvelt KM, Colaiacovo MP, Church GM, Calarco JA. Heritable genome editing in C. elegans via a CRISPR-Cas9 system. Nat Methods (2013) 10(8):741-3. doi: 10.1038/nmeth.2532

21. Dickinson DJ, Ward JD, Reiner DJ, Goldstein B. Engineering the Caenorhabditis elegans genome using Cas9-triggered homologous recombination. Nat Methods (2013) 10(10):1028-34. doi: 10.1038/ nmeth.2641

22. Kadandale P, Chatterjee I, Singson A. Germline transformation of Caenorhabditis elegans by injection. Methods Mol Biol (2009) 518:123-33. doi: 10.1007/978-1-59745-202-1_10

23. Mello C, Kramer J, Stinchcomb D, Ambros V. Efficient gene transfer in C.elegans: extra chromosomal maintenance and integration of transforming sequences. EMBO J (1991) 10(12):3959-70. doi: 10.1002/j.14602075.1991.tb04966.x

24. Brenner S. The genetics of Caenorhabditis elegans. Genetics (1974) 77(1):71-94.

25. Schulenburg H, Hoeppner MP, Weiner J,3, Bornberg-Bauer E. Specificity of the innate immune system and diversity of C-type lectin domain (CTLD) proteins in the nematode Caenorhabditis elegans. Immunobiology (2008) 213 (3-4):237-50. doi: 10.1016/j.imbio.2007.12.004

26. Kuo CJ, Chen JW, Chiu HC, Teng CH, Hsu TI, Lu PJ, et al. Mutation of the Enterohemorrhagic Escherichia coli Core LPS Biosynthesis Enzyme RfaD Confers Hypersusceptibility to Host Intestinal Innate Immunity In vivo. Front Cell Infect Microbiol (2016) 6:82. doi: 10.3389/fcimb.2016.00082

27. Kuo CJ, Wang ST, Lin CM, Chiu HC, Huang CR, Lee DY, et al. A multi-omic analysis reveals the role of fumarate in regulating the virulence of enterohemorrhagic Escherichia coli. Cell Death Dis (2018) 9(3):381. doi: 10.1038/s41419-018-0423-2

28. Chang HC, Paek J, Kim DH. Natural polymorphisms in C. elegans HECW-1 E3 ligase affect pathogen avoidance behaviour. Nature (2011) 480(7378):5259. doi: $10.1038 /$ nature 10643

29. Brandt JP, Ringstad N. Toll-like Receptor Signaling Promotes Development and Function of Sensory Neurons Required for a C. elegans PathogenAvoidance Behavior. Curr Biol (2015) 25(17):2228-37. doi: 10.1016/ j.cub.2015.07.037

30. Chen HD, Kao CY, Liu BY, Huang SW, Kuo CJ, Ruan JW, et al. HLH-30/TFEBmediated autophagy functions in a cell-autonomous manner for epithelium intrinsic cellular defense against bacterial pore-forming toxin in C. elegans. Autophagy (2017) 13(2):371-85. doi: 10.1080/15548627.2016.1256933

31. Cheesman HK, Feinbaum RL, Thekkiniath J, Dowen RH, Conery AL, PukkilaWorley R. Aberrant Activation of p38 MAP Kinase-Dependent Innate Immune Responses Is Toxic to Caenorhabditis elegans. G3: Genes $\mid$ Genomes| Genetics (2016) 6(3):541-9. doi: 10.1534/g3.115.025650

32. Alper S, McBride SJ, Lackford B, Freedman JH, Schwartz DA. Specificity and complexity of the Caenorhabditis elegans innate immune response. Mol Cell Biol (2007) 27(15):5544-53. doi: 10.1128/MCB.02070-06
33. Pukkila-Worley R, Feinbaum R, Kirienko NV, Larkins-Ford J, Conery AL, Ausubel FM. Stimulation of host immune defenses by a small molecule protects C. elegans from bacterial infection. PLoS Genet (2012) 8(6): e1002733. doi: 10.1371/journal.pgen.1002733

34. Svensk E, Devkota R, Stahlman M, Ranji P, Rauthan M, Magnusson F, et al. Caenorhabditis elegans PAQR-2 and IGLR-2 Protect against Glucose Toxicity by Modulating Membrane Lipid Composition. PLoS Genet (2016) 12(4): e1005982. doi: 10.1371/journal.pgen.1005982

35. Reddy K, Andersen E, Kruglyak L, Kim D. A Polymorphism in npr-1 Is a Behavioral Determinant of Pathogen Susceptibility in C. elegans. Science (2009) 323(5912):382-4. doi: 10.1126/science.1166527

36. Clark LC, Hodgkin J. Commensals, probiotics and pathogens in the Caenorhabditis elegans model. Cell Microbiol (2014) 16(1):27-38. doi: $10.1111 / \mathrm{cmi} .12234$

37. Tan M-W, Mahajan-Miklos S, Ausubel FM. Killing of Caenorhabditis elegans by Pseudomonas aeruginosa used to model mammalian bacterial pathogenesis. Proc Natl Acad Sci U S A (1999) 96(2):715-20. doi: 10.1073/ pnas.96.2.715

38. Irazoqui JE, Urbach JM, Ausubel FM. Evolution of host innate defence: insights from Caenorhabditis elegans and primitive invertebrates. Nat Rev Immunol (2010) 10(1):47-58. doi: 10.1038/nri2689

39. Kuo CJ, Hansen M, Troemel E. Autophagy and innate immunity: Insights from invertebrate model organisms. Autophagy (2018) 14(2):233-42. doi: 10.1080/15548627.2017.1389824

40. Sim S, Hibberd ML. Caenorhabditis elegans susceptibility to gut Enterococcus faecalis infection is associated with fat metabolism and epithelial junction integrity. BMC Microbiol (2016) 16:6. doi: 10.1186/s12866-016-0624-8

41. Dasgupta M, Shashikanth M, Gupta A, Sandhu A, De A, Javed S, et al. NHR49 Transcription Factor Regulates Immunometabolic Response and Survival of Caenorhabditis elegans during Enterococcus faecalis Infection. Infect Immun (2020) 88(8):1-16. doi: 10.1128/IAI.00130-20

42. Svensk E, Biermann J, Hammarsten S, Magnusson F, Pilon M. Leveraging the withered tail tip phenotype in C. elegans to identify proteins that influence membrane properties. Worm (2016) 5(3):e1206171. doi: 10.1080/ 21624054.2016.1206171

43. Bodhicharla R, Devkota R, Ruiz M, Pilon M. Membrane Fluidity Is Regulated Cell Nonautonomously by Caenorhabditis elegans PAQR-2 and Its Mammalian Homolog AdipoR2. Genetics (2018) 210(1):189-201. doi: 10.1534/genetics.118.301272

44. Zanetti S, Meola M, Bochud A, Puoti A. Role of the C. elegans U2 snRNP protein MOG-2 in sex determination, meiosis, and splice site selection. Dev Biol (2011) 354(2):232-41. doi: 10.1016/j.ydbio.2011.04.001

45. Selfors L, Schutzman J, Borland C, Stern M. soc-2 encodes a leucine-rich repeat protein implicated in fibroblast growth factor receptor signaling. Proc Natl Acad Sci U S A (1998) 95(12):6903-8. doi: 10.1073/pnas.95.12.6903

46. Dixon SJ, Alexander M, Fernandes R, Ricker N, Roy PJ. FGF negatively regulates muscle membrane extension in Caenorhabditis elegans. Development (2006) 133(7):1263-75. doi: 10.1242/dev.02300

47. Gotenstein JR, Swale RE, Fukuda T, Wu Z, Giurumescu CA, Goncharov A, et al. The C. elegans peroxidasin PXN-2 is essential for embryonic morphogenesis and inhibits adult axon regeneration. Development (2010) 137(21):3603-13. doi: 10.1242/dev.049189

48. Piano F, Schetter A, Morton D, Gunsalus K, Reinke V, Kim S, et al. Gene Clustering Based on RNAi Phenotypes of Ovary-Enriched Genes in C. elegans. Curr Biol (2002) 12(22):1259-64. doi: 10.1016/S0960-9822(02)01301-5

49. Peel N, Iyer J, Naik A, Dougherty MP, Decker M, O'Connell KF. Protein Phosphatase 1 Down Regulates ZYG-1 Levels to Limit Centriole Duplication. PLoS Genet (2017) 13(1):e1006543. doi: 10.1371/journal.pgen.1006543

50. Kaji H, Kamiie J, Kawakami H, Kido K, Yamauchi Y, Shinkawa T, et al. Proteomics reveals N-linked glycoprotein diversity in Caenorhabditis elegans and suggests an atypical translocation mechanism for integral membrane proteins. Mol Cell Proteomics (2007) 6(12):2100-9. doi: 10.1074/ mcp.M600392-MCP200

51. Ceron J, Rual JF, Chandra A, Dupuy D, Vidal M, van den Heuvel S. Largescale RNAi screens identify novel genes that interact with the C. elegans retinoblastoma pathway as well as splicing-related components with synMuv B activity. BMC Dev Biol (2007) 7:30. doi: 10.1186/1471-213X-7-30 
52. Altincicek B, Fischer M, Fischer M, Luersen K, Boll M, Wenzel U, et al. Role of matrix metalloproteinase ZMP-2 in pathogen resistance and development in Caenorhabditis elegans. Dev Comp Immunol (2010) 34(11):1160-9. doi: 10.1016/j.dci.2010.06.010

53. Boulin T, Etchberger JF, Hobert O. Reporter gene fusions. In: WormBook (2006). p. 1-23. Available at: https://www.scimagojr.com/journalsearch.php? $\mathrm{q}=10300153339 \& \mathrm{tip}=$ sid\&clean $=0$

54. Ewbank JJ, Pujol N. Local and long-range activation of innate immunity by infection and damage in C. elegans. Curr Opin Immunol (2016) 38:1-7. doi: $10.1016 /$ j.coi.2015.09.005

55. Couillault C, Pujol N, Reboul J, Sabatier L, Guichou JF, Kohara Y, et al. TLRindependent control of innate immunity in Caenorhabditis elegans by the TIR domain adaptor protein TIR-1, an ortholog of human SARM. Nat Immunol (2004) 5(5):488-94. doi: 10.1038/ni1060
56. Wang X, Zhao X, Yan C, Jia Z, Lv Z, Ma C, et al. A novel LRR and Ig domaincontaining protein could function as an immune effector in Crassostrea gigas. Fish Shellfish Immunol (2019) 88:318-27. doi: 10.1016/j.fsi.2019.03.003

Conflict of Interest: The authors declare that the research was conducted in the absence of any commercial or financial relationships that could be construed as a potential conflict of interest.

Copyright $\odot 2020 \mathrm{Kuo}, \mathrm{Hsu}$, Wang, Liou, Lim, Chen and Chen. This is an open-access article distributed under the terms of the Creative Commons Attribution License (CC BY). The use, distribution or reproduction in other forums is permitted, provided the original author(s) and the copyright owner(s) are credited and that the original publication in this journal is cited, in accordance with accepted academic practice. No use, distribution or reproduction is permitted which does not comply with these terms. 